\title{
Modelo curricular formativo e integrativo na Odontologia: uma análise do ensino da Biossegurança
}

\author{
A Formative and Integrating Curricular \\ Template in Dentistry: an Analysis of Teaching Biosafety
}

Leda Freitas de Jesus ${ }^{1}$

Volney de Magalhães Câmara ${ }^{2}$

Resumo: As medidas de Biossegurança para prevenção e proteção contra os riscos ocupacionais na Odontologia são aprendidas durante o período de graduação. A importância de tais medidas ficou evidente na pandemia de COVID-19. Esta pesquisa transversal, exploratória e descritiva objetivou analisar a Biossegurança como componente curricular das faculdades de Odontologia brasileiras. População de estudo composta por coordenadores de cursos de graduação em Odontologia do Brasil. Coleta de dados por meio de um questionário online, entre novembro/2019 e fevereiro/2020. Os resultados foram analisados de forma descritiva e agregada. Dos 68 cursos respondentes, em 43 havia disciplina específica para Biossegurança, todas obrigatórias, 5 teóricas e 38 teórico-práticas. Principais motivos para existência da disciplina específica: importante para a formação/exercício profissional; estabelecimento de boas práticas de trabalho; apresentar conceitos/normas. Principal motivo para não haver disciplina específica: adoção de currículo integrado/interdisciplinar. Conteúdo programático mais extenso nos cursos com disciplina específica, com predomínio de tópicos relacionados a prevenção e controle de infecção em ambos os grupos. Entre as referências bibliográficas adotadas, houve predominância de livros-texto e de manuscritos produzidos por instituições governamentais brasileiras, com a maioria dos cursos informando revisarem rotineiramente as referências. Identificaram-se 28 nomenclaturas para a disciplina, ofertada principalmente nos períodos iniciais do curso e como prérequisito para outras disciplinas. Considera-se ideal que no currículo dos cursos de graduação em Odontologia conste uma disciplina específica para Biossegurança, obrigatória, no primeiro ano e com reforço do tema ao longo do curso, principalmente nas disciplinas com atividades práticas. Sugerem-se alguns tópicos sobre Biossegurança para o conteúdo curricular.

Palavras-chave: Currículo. Educação em Odontologia. Cirurgião-dentista. 
Abstract: Biosafety measures for prevention and protection against occupational risks in Dentistry are learned during the graduation period. The importance of such measures has become even more clear during the COVID-19 pandemic. We conducted a transversal, exploratory, descriptive research with the purpose of analyzing the topic of biosafety as part of the Brazilian Dental Schools' curriculum. The population study was composed of individuals who work as coordinators of 68 Dentistry undergraduate programs. All the data was collected through an online questionnaire between November 2019 and February 2020. The results were analyzed through descriptive and aggregate methods. There were specific, mandatory courses on Biosafety in 43 of the 68 programs, 5 of them being theoretical while 38 were theoreticalpractical courses. The respondents mainly listed the following reasons for the existence of a specific course: the relevance for professional education/practice, the establishment of best practices, and the presentation of concepts/norms. We found that the main reason for the lack of a specific course was the adoption of an integrated/interdisciplinary program. The curricular content is more comprehensive in the programs that offer specific courses on biosafety, with the most predominant topics in both types of courses being related to infection prevention and control. Among the listed bibliographic references, Brazilian governmental institutions' textbooks and manuscripts prevailed, and most programs informed that these references are frequently revised. We identified 28 different course names, which are mostly offered at the beginning of the program and as prerequisites for other courses. We consider it ideal to include a mandatory specific course on biosafety to be taken during the Dentistry undergraduate programs, as well as to reinforce the topic throughout the program, mainly in the practical courses. We also suggest some topics on biosafety to be included in the curricular content.

Keywords: Curriculum. Education. Dental. Dentists.

${ }^{1}$ Fundação Oswaldo Cruz | Escola Nacional de Saúde Pública Sérgio Arouca | Rio de Janeiro | RJ | Brasil. Contato: leda.dfj@gmail.com. ORCID: https://orcid.org/0000-0001-6935-4040

${ }^{2}$ Universidade Federal do Rio de Janeiro | Instituto de Estudos em Saúde Coletiva | Rio de Janeiro | RJ | Brasil. Contato: camaravolney@gmail.com. ORCID: https://orcid.org/0000-0002-6596-6653

- Recebido em: 9 de dezembro de 2020

- Aprovado em: 23 de junho de 2021

DOI: http://dx.doi.org/10.1590/S1414-40772021000300014

Este é um artigo publicado em acesso aberto sob uma licença Creative Commons https://creativecommons.org/licenses/by-nc/4.0/ 


\section{Introdução}

A prática odontológica gera uma variedade de riscos à saúde dos cirurgiões-dentistas (CD), que podem resultar em acidentes ou doenças ocupacionais capazes de causar efeitos adversos para a saúde desses profissionais (EU-OSHA, 2017; ŞOAITA, 2014). Para controlar e minimizar tais riscos na rotina do trabalho odontológico é necessário que a prática profissional seja baseada na Biossegurança. Em Odontologia, Biossegurança constitui-se em um conjunto de medidas de controle dos riscos ocupacionais, princípios de controle da infecção e práticas ergonômicas que buscam garantir que a assistência à saúde bucal aconteça sob condições adequadas de segurança para o profissional, o paciente e o ambiente (SILVA; RIBEIRO; RISSO, 2009). Estas medidas, princípios e práticas são aprendidas durante o processo de formação profissional, destacando que, segundo Pimentel et al. (2012), o CD tende a seguir na vida profissional os hábitos adotados durante a vida acadêmica. Ressalte-se que a pandemia de COVID-19 evidenciou a importância da Biossegurança para a segurança das atividades odontológicas (ADA, 2020).

Contudo, o número de notificações de acidentes ocupacionais envolvendo CDs brasileiros é alto (MPT; OIT, 2020), apesar da reconhecida subnotificação desses acidentes (MUSSI; MARASEA, 2016; NOGUEIRA et al., 2016). Além disso, na literatura existem diversos relatos sobre $\mathrm{CDs}$ e alunos de Odontologia com práticas que denotam desconhecimento e/ou descuido com relação à Biossegurança, bem como estudos que consideraram insuficientes os conteúdos e/ou disciplinas sobre o tema em certas instituições de ensino superior (IES) (LOPES et al., 2019; MAZUTTI; FREDDO; LUCIETTO, 2018; KUHN et al., 2018; OLIVEIRA et al., 2017). Tais fatores podem estar apontando para a possibilidade de haver cursos de Odontologia em que a formação não esteja favorecendo a assimilação e/ou consolidação dos conhecimentos sobre Biossegurança, que são essenciais ao exercício seguro da profissão.

A presença da disciplina Biossegurança no currículo da graduação em Odontologia pode influenciar positivamente na formação e manutenção de práticas seguras no cotidiano da atividade odontológica, visto que incutir conceitos e princípios, como os de Biossegurança, durante um período acadêmico formativo, além de ser mais fácil do que em profissionais que já se encontram atuantes, é um primeiro passo lógico na construção de uma cultura de responsabilidade (MANCINI; REVILL, 2008). Desta forma, esta pesquisa se propôs a analisar a Biossegurança em disciplinas, específicas e não específicas, como componente curricular das faculdades de Odontologia do Brasil. 


\section{Metodologia}

Pesquisa transversal, exploratória e descritiva. A população de estudo foi composta por coordenadores de cursos de graduação em Odontologia do Brasil dos quais foi possível obter um e-mail de contato nos sites das faculdades ou por meio de mensagem eletrônica para as IES.

A coleta de dados foi realizada por meio de um questionário online na plataforma Google Drive, autoaplicável e padronizado, contendo 22 questões (11 fechadas e 11 abertas). As questões visaram obter informações relacionadas ao ensino da Biossegurança nas faculdades: I) existência de disciplinas específicas obrigatórias ou eletivas sobre o tema; organização da disciplina; II) ensino de Biossegurança em outras disciplinas e como ela é apresentada na disciplina em que está inserida; III) referências bibliográficas utilizadas.

Após um pré-teste com um grupo semelhante ao da pesquisa real, uma mensagemconvite para participação da pesquisa, contendo o link para o questionário e o Termo de Consentimento Livre e Esclarecido anexado, foi enviada por $e$-mail a 302 coordenadores, tendo ficado disponível para preenchimento de novembro/2019 a fevereiro/2020. Durante esse período, na expectativa de obter um maior número de adesões à pesquisa, a mensagem-convite com o questionário foi reenviada duas vezes. As respostas ficaram arquivadas na plataforma virtual até o encerramento do recebimento, quando foram exportadas para uma planilha eletrônica e analisadas.

Todas as variáveis foram analisadas sob a perspectiva estritamente descritiva, sem aplicação de avaliação estatística e de inferência ou generalização de resultados.

Esta pesquisa foi aprovada pelo Comitê de Ética em Pesquisa do Instituto de Estudos em Saúde Coletiva / Universidade Federal do Rio de Janeiro (CAAE: 06143218.3.0000.5286).

\section{Resultados e discussão}

Responderam o questionário 68 coordenadores (22,5\%). A figura 1 ilustra a distribuição dos cursos investigados segundo a existência ou não de disciplina específica para o ensino de Biossegurança nos currículos, a natureza da disciplina (obrigatória ou eletiva) e o método de ensino aprendizagem utilizado (teórica ou teórico-prática).

Figura 1 - Disciplina específica para o ensino de Biossegurança no currículo dos cursos investigados, segundo existência, natureza e método de ensino-aprendizagem

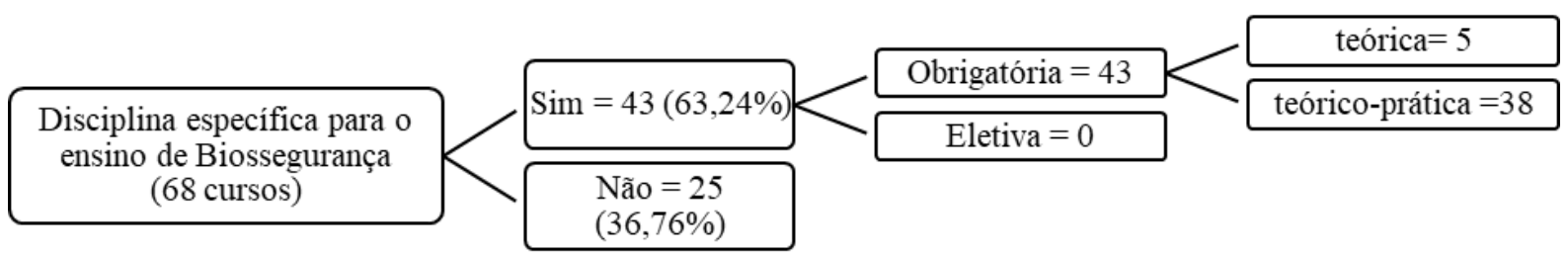


O baixo número de respondentes já era esperado, visto que questionários online apresentam, por motivos variados, índice de resposta inferior a outros métodos de aplicação (VASCONCELLOS; GUEDES, 2007). Outros estudos que tiveram coordenadores de cursos de graduação como população de estudo também obtiveram baixo percentual de retorno de questionários (OLIVEIRA, 2018; ROCHA; SCHUH; MACHADO, 2019).

O currículo não é um fim, mas sim um meio para promoção de uma aprendizagem de qualidade (UNESCO, 2016). As novas Diretrizes Curriculares Nacionais (DCN) do curso de graduação em Odontologia (BRASIL, 2018) recomendam que a organização curricular seja orientada por objetivos formativos focados no perfil do egresso com capacidade de associar conhecimentos, habilidades e atitudes necessárias à compreensão da totalidade do indivíduo e à uma atuação humanizada na prevenção e promoção da saúde na sua área de atuação, ratificando estudos sobre o tema (MORAES; COSTA, 2016; TAVARES et al., 2016).

É recomendado que os currículos dos cursos de formação em Odontologia sejam continuamente reavaliados e reestruturados, para se adaptarem à constante evolução do conhecimento e da biotecnologia, bem como para buscarem uma educação integral, mais humanizada, vinculada à realidade e com qualidade técnico-científica (MORAES; COSTA, 2016; TOASSI et al., 2012).

A unanimidade de respostas sobre a natureza obrigatória da disciplina específica mostra que é ponto pacífico a fundamentalidade de sedimentar o conhecimento sobre Biossegurança nos alunos de graduação em Odontologia, em consonância com outros estudos sobre o assunto que recomendaram a obrigatoriedade da disciplina (BELLISSIMO-RODRIGUES; BELLISSIMO-RODRIGUES; MACHADO, 2010; RIBEIRO, 2004; ZENKNER, 2006). Arantes et al. (2015) e Lopes et al (2019) enfatizaram a importância da disciplina de Biossegurança na conscientização dos futuros profissionais acerca da necessidade de respeitar permanentemente as medidas de prevenção e proteção contra os riscos ocupacionais envolvidos na prática odontológica. Pesquisa realizada em 142 cursos de 57 universidades em 29 países concluiu que a Biossegurança precisa fazer parte do currículo básico obrigatório dos cursos de ciências da vida, o que incluiu a Odontologia, a fim de desenvolver nos alunos uma cultura de responsabilidade social e ambiental (MANCINI; REVILL, 2008). Porém, mesmo com tantas pesquisas evidenciando a importância da Biossegurança para a prática odontológica, nas novas DCNs (BRASIL, 2018) não consta a obrigatoriedade dessa disciplina, havendo somente a sua citação como conteúdo curricular essencial.

A alternância entre disciplinas/atividades teóricas e disciplinas/atividades práticas implica na suposição de que o aluno é capaz de interconectar o que foi ensinado durante as 
aulas com o que é vivenciado na rotina de trabalho, além de poder resultar em distanciamento entre o ensino da teoria e da prática, fragmentação do conhecimento e insatisfação de alunos e egressos (ARMOND et al., 2016; MORAES; COSTA, 2016). Nesse sentido, um currículo onde haja articulação permanente entre a teoria e a sua aplicação na clínica odontológica permite um aprendizado mais contextualizado, que leva à formação de profissionais com pensamento crítico e reflexivo acerca da prática profissional ética e segura (NORO et al., 2017), conforme recomendado pelas DCN (BRASIL, 2018).

Estudos sugeriram a inclusão de um supervisor para garantir a efetiva aplicação das normas de Biossegurança durante as atividades clínicas, considerando que a obrigatoriedade e a supervisão costumam resultar em maior adesão de estudantes às referidas normas (LAGES et al., 2015; LOPES et al., 2019; RIBEIRO, 2004).

Após responder à primeira questão - sobre existência de disciplina específica para a Biossegurança no currículo do curso - o respondente era direcionado automaticamente para a seção subsequente à resposta afirmativa ou negativa. Por isso, os demais resultados foram organizados em três partes: i) todos os cursos; ii) cursos com disciplina específica para Biossegurança no currículo; iii) cursos sem disciplina específica para Biossegurança no currículo.

\subsection{Todos os cursos}

Os motivos citados pelos coordenadores para a existência ou não de uma disciplina específica para o ensino de Biossegurança no currículo dos cursos foram organizados em categorias, conforme a semelhança das respostas. Algumas se enquadraram em mais de uma categoria. Os motivos são apresentados no quadro 1. 
Quadro 1 - Motivos apresentados pelos coordenadores dos cursos de Odontologia para a existência ou não de disciplina específica para o ensino de Biossegurança no currículo do curso, Brasil, 2019.

\begin{tabular}{|c|c|c|}
\hline $\begin{array}{l}\text { Currículo com } \\
\text { disciplina } \\
\text { específica para } \\
\text { Biossegurança }\end{array}$ & Categorias & $\mathbf{N}$ \\
\hline \multirow[t]{14}{*}{ Sim } & $\begin{array}{l}\text { Importante/básico/fundamental/elementar para a formação e/ou o exercício da } \\
\text { profissão }\end{array}$ & 24 \\
\hline & $\begin{array}{l}\text { Estabelecimento de boas práticas de trabalho durante o curso e na rotina } \\
\text { profissional }\end{array}$ & 10 \\
\hline & $\begin{array}{l}\text { Importante apresentar conceitos, instruir sobre normas e procedimentos, } \\
\text { uniformizar ações }\end{array}$ & 5 \\
\hline & $\begin{array}{l}\text { Capacitação/orientação/desenvolvimento de competências para lidar com o } \\
\text { risco de infecção/contaminação/disseminação de doenças durante o curso e na } \\
\text { rotina profissional }\end{array}$ & 5 \\
\hline & Conhecimento necessário previamente à atividade clínica & 4 \\
\hline & $\begin{array}{l}\text { Proteção/segurança de profissionais, pacientes, ambiente de trabalho, meio } \\
\text { ambiente }\end{array}$ & 4 \\
\hline & Controle de riscos para CDs, equipe de trabalho e pacientes & 3 \\
\hline & Estímulo à responsabilidade/consciência crítica/ética/bioética & 2 \\
\hline & Necessária para cursos da área de saúde & 2 \\
\hline & Aprendizagem e execução de todo o processo de esterilização & 1 \\
\hline & Cumprimento das DCN & 1 \\
\hline & $\begin{array}{l}\text { Desenvolvimento de competências relacionadas à promoção, prevenção e } \\
\text { recuperação da saúde bucal }\end{array}$ & 1 \\
\hline & Sem resposta & 1 \\
\hline & Valorização das condições de trabalho & 1 \\
\hline \multirow[t]{5}{*}{ Não } & $\begin{array}{l}\text { A faculdade adota o modelo de currículo integrado, onde a Biossegurança é } \\
\text { trabalhada em outras disciplinas, teóricas e práticas, ao longo do curso, assim } \\
\text { como os estágios / cada disciplina assume a sua parte no conteúdo / assunto é } \\
\text { abordado como conteúdo programático de outras disciplinas, cada uma } \\
\text { expondo a sua especificidade }\end{array}$ & 19 \\
\hline & Porque ultrapassaria a carga horária do curso previsto no PPC & 3 \\
\hline & É abordado em outra disciplina & 2 \\
\hline & Porque ainda não foi criada & 1 \\
\hline & A grade curricular foi montada por outra coordenação & 1 \\
\hline
\end{tabular}

Na maioria dos cursos investigados havia disciplina específica para Biossegurança, corroborando o achado de Bellissimo-Rodrigues; Bellissimo-Rodrigues; Machado (2010) sobre o aumento na oferta dessa disciplina nos cursos de graduação de Odontologia. Para Ribeiro (2004), uma disciplina específica para Biossegurança no currículo seria um meio salutar de sistematizar a promoção do aprendizado sobre o tema. Para Gomes et al. (2014), caso não haja uma disciplina específica, a Biossegurança deve ser obrigatoriamente abordada em outra(s) $\operatorname{disciplina(s).}$

A adoção de um currículo integrado/interdisciplinar, no qual a Biossegurança faz parte do conteúdo programático de outras disciplinas, consistiu no motivo mais citado (73\%) para a inexistência de uma disciplina específica para o tema. Esta forma de organização curricular tem disso defendida por diversos estudos, com base no argumento de que o desenvolvimento de 
habilidades e competências gerais e específicas para o exercício das profissões da saúde envolve diferentes campos do conhecimento, além de ser permeado pela IES e pelos docentes (MORAES; COSTA, 2016; SOUZA; LOPES; LIMA FILHO, 2017), visto que a Biossegurança não se resume somente a normas de prevenção e controle.

De acordo com Costa Neto (2006), a graduação em Odontologia deve adotar um modelo curricular baseado na integralidade/interdisciplinaridade, com os componentes curriculares articulados: i) verticalmente, para que haja uma sequência de conteúdos a serem ministrados, em grau crescente de complexidade, ao longo de todo o curso; ii) horizontalmente, para conectar os conteúdos programáticos ofertados em um mesmo semestre/período. Para Noro et al. (2017), o currículo integrado deve conferir maior importância à aprendizagem contextualizada pelo aluno do que à provisão do conhecimento específico de uma única disciplina. Tal organização, segundo Cezarino e Corrêa (2019), pode beneficiar o aluno por capacitá-lo a articular e empregar conhecimentos na busca de soluções no seu cotidiano de trabalho.

$\mathrm{Na}$ literatura, entretanto, são rotineiramente encontrados estudos que observaram alunos e profissionais da Odontologia com conhecimento insatisfatório sobre Biossegurança (LOPES et al., 2019; OLIVEIRA et al., 2017). Nesse contexto, existem alertas sobre a necessidade de aprimoramento do ensino da Biossegurança nos cursos de Odontologia, tanto em disciplinas específicas quanto nas de abordagem interdisciplinar, de modo a melhorar a assimilação e a sedimentação do conhecimento, bem como a adesão às práticas de Biossegurança pelos profissionais em formação e formados (ARMOND et al., 2016; BELLISSIMO-RODRIGUES; BELLISSIMO-RODRIGUES; MACHADO, 2010; GOMES et al., 2014; RIBEIRO, 2004; TREZENA et al., 2019). Destaque-se que o aprimoramento do ensino inclui aulas ministradas por docentes com formação em Biossegurança e que utilizem estratégias educativas motivadoras, bem como capacitação de todos os trabalhadores de todas as categorias profissionais que atuam na clínica e que também precisam seguir normas e protocolos de Biossegurança (ARMOND et al., 2016; RIBEIRO, 2004).

As informações coletadas junto aos coordenadores sobre o conteúdo programático da disciplina específica para o ensino de Biossegurança, bem como sobre os tópicos sobre o tema ministrados nas disciplinas não específicas foram agrupadas em 30 categorias, conforme as semelhanças das respostas (Quadro 2): 
Quadro 2 - Tópicos sobre Biossegurança ministrados nas disciplinas específicas e nas não específicas para o ensino de Biossegurança nas faculdades de Odontologia investigadas, Brasil, 2019.

\begin{tabular}{|c|c|c|}
\hline \multirow[b]{2}{*}{ Categorias } & \multicolumn{2}{|c|}{$\mathbf{N}$} \\
\hline & $\begin{array}{l}\text { Cursos com } \\
\text { disciplina } \\
\text { específica }\end{array}$ & $\begin{array}{l}\text { Cursos } \\
\text { sem } \\
\text { disciplina } \\
\text { específica }\end{array}$ \\
\hline Precauções-padrão/Protocolos/Conduta em ambiente clínico & 31 & 19 \\
\hline $\begin{array}{l}\text { Preparo do ambiente clínico / Montagem do equipo (crítico e semicrítico) / } \\
\text { Processamento de instrumentais odontológicos / Controle de contaminação } \\
\text { e infecção em ambiente odontológico / Gestão da qualidade }\end{array}$ & 30 & 37 \\
\hline Riscos ocupacionais & 24 & 8 \\
\hline Gerenciamento de resíduos / Educação ambiental & 23 & 7 \\
\hline $\begin{array}{l}\text { Acidente com perfurocortante/exposição a material biológico: } \\
\text { prevenção/conduta pós-acidente }\end{array}$ & 16 & 1 \\
\hline $\begin{array}{l}\text { Doenças infecciosas/transmissíveis e não infeciosas/não transmissíveis na } \\
\text { prática odontológica / Tecnopatias na prática odontológica }\end{array}$ & 16 & 3 \\
\hline Conceitos/Terminologia/Princípios básicos/História & 13 & 3 \\
\hline Ergonomia / Instalação do consultório odontológico & 12 & 1 \\
\hline Legislação/Normas & 11 & 3 \\
\hline Imunização & 10 & 7 \\
\hline Biossegurança em Odontologia & 7 & 5 \\
\hline Saúde ocupacional/Saúde do trabalhador & 5 & - \\
\hline Atendimento a situações de emergência & 2 & - \\
\hline Documentação odontológica & 2 & - \\
\hline Órgão dental / bancos de dentes & 2 & 1 \\
\hline Segurança do paciente & 2 & - \\
\hline $\begin{array}{l}\text { Anatomia, Histologia, Bioquímica e Genética e Microbiologia em } \\
\text { Odontologia }\end{array}$ & 1 & - \\
\hline Atenção primária à saúde/à saúde bucal & 1 & - \\
\hline $\begin{array}{l}\text { Atividades práticas e metodologias ativas visando aplicação dos conceitos } \\
\text { teóricos }\end{array}$ & 1 & - \\
\hline Bioética & 1 & - \\
\hline CIPA & 1 & - \\
\hline Comissão de controle de infecção Odontológica & 1 & - \\
\hline Controle da qualidade da água e do ar & 1 & - \\
\hline Humanização na saúde & 1 & - \\
\hline Instruções de higiene oral e enxaguatórios bucais & 1 & - \\
\hline Mercado de trabalho & 1 & - \\
\hline Microbiologia em Odontologia & 1 & - \\
\hline Prevenção de cárie e doença periodontal & 1 & - \\
\hline Princípios biológicos do indivíduo saudável & 1 & - \\
\hline Razão, meios e aplicabilidade clínica & 1 & - \\
\hline Sem resposta / Não recorda & 4 & 2 \\
\hline
\end{tabular}

A partir da análise dos tópicos sobre Biossegurança ministrados, verificou-se um conteúdo mais substancial sobre o tema nos cursos em que há uma disciplina específica, em comparação com aqueles em que a Biossegurança não consta no currículo como disciplina. Bellissimo-Rodrigues, Bellissimo-Rodrigues e Machado (2010) advertiram que sem uma disciplina específica, há o risco de o conteúdo sobre Biossegurança ficar diluído em outras disciplinas e ser ensinado de forma desestruturada, sem uma abordagem efetiva. Para Zenckner (2006), colocar a Biossegurança dentro de outra disciplina de certa forma desmerece a 
importância do tema. Meireles e Lindino (2020) observaram maior percepção de conhecimento entre acadêmicos que estudaram o tema investigado em uma disciplina específica em comparação aos que o estudaram integrado a outras disciplinas.

Percebe-se que no currículo de ambos os tipos de cursos há predominância de tópicos relacionados a prevenção e controle de infecção, o que pode ser considerado acertado, posto que a contaminação por micro-organismos patogênicos é um dos principais riscos relacionados ao trabalho odontológico (ARMOND et al., 2016; KUHN et al., 2018; TREZENA et al., 2019). O tópico sobre imunização recebeu pouca, mas similar citação dos coordenadores dos dois tipos de cursos, corroborando estudos que destacaram a importância desse tema e até sugeriram cobrança do esquema vacinal completo para todos os envolvidos nas atividades clínicas, especialmente os discentes (ARMOND et al., 2016; MAZUTTI; FREDDO; LUCIETTO, 2018).

Por outro lado, pode ser preocupante o fato de entre os cursos sem disciplina específica haver apenas uma citação a acidente com perfurocortante/exposição a material biológico: prevenção/conduta pós-acidente. Este tipo de acidente ocupacional tem alta frequência entre CDs e também alunos de Odontologia (MAZUTTI; FREDDO; LUCIETTO, 2018; NOGUEIRA et al., 2016), motivo pelo qual entende-se como altamente relevante que o tópico faça parte do conteúdo programático da formação em Odontologia. Nos demais tópicos, também foi verificada uma maior citação dos cursos com disciplina específica em comparação aos sem disciplina específica, sugerindo que naqueles que contam com uma disciplina exclusiva para o tema há uma abordagem mais enfática da Biossegurança.

Foi perguntado se a faculdade indicava aos alunos referências bibliográficas sobre Biossegurança. Dentre aquelas que possuíam disciplina específica, 42 responderam sim e apenas 01 respondeu não. Já entre as que não possuíam disciplina específica, 23 afirmaram indicar referências sobre o tema, 03 disseram que não indicavam e 01 coordenador não respondeu. Todas as referências citadas foram checadas, o que permitiu detectar e excluir da relação final duas referências desatualizadas e uma que não foi possível ser identificada.

Assim, verificou-se um total de 100 referências bibliográficas, entre livros-texto contendo conceitos e fundamentos (54), manuais técnicos (21), legislações (8), artigos científicos (5), manual ou procedimento operacional padrão (POP) elaborado pela própria instituição (3), protocolo (1) e termos genéricos sem especificação de título e autor (8). Em ambos os grupos, houve maior citação para livros-texto, com predominância de alguns clássicos sobre Biossegurança em Odontologia, tais como Naressi, Orenha e Naressi (2013) (18), Silva, Ribeiro e Risso (2009) (16), Hirata, Hirata e Mancini Filho (2016) (12) e Estrela e Estrela 
(2003) (4). No quesito legislação, a mais citada foi a Portaria 1.748/2011, que dispõe sobre a Norma Regulamentadora Nº 32 (NR-32) e o Plano de Prevenção de Riscos de Acidentes com Materiais Perfurocortantes (BRASIL, 2011). Acerca da autoria, houve predominância de textos de instituições do governo brasileiro, com um total de 27 documentos, incluindo manuais técnicos, protocolo e legislação sobre o tema, com destaque para o manual técnico da Agência Nacional de Vigilância Sanitária (ANVISA, 2006) sobre prevenção e controle de riscos nos serviços odontológicos (11).

Os coordenadores dos cursos com disciplina específica citaram 85 diferentes referências, divididas entre livros-texto com conceitos e fundamentos (50), manuais técnicos (21), legislações (8), artigos científicos (5) e protocolo (1). Houve um maior número de citações de textos produzidos por instituições governamentais brasileiras (24). Dentre as publicações não-governamentais, os autores mais citados foram Silva Ribeiro e Risso (2009) (13), Naressi, Orenha e Naressi (2013) (11) e Hirata, Hirata e Mancini Filho (2016) (8).

Para os cursos sem disciplina específica para Biossegurança, os coordenadores citaram 21 diferentes referências, divididas entre livros-texto contendo conceitos e fundamentos (8), manuais técnicos (2), manual/POP elaborado pela própria instituição (3), termos genéricos sem título/autor (8). Nesse grupo, os autores mais citados foram Naressi, Orenha e Naressi (2013) (7), Hirata, Hirata e Mancini Filho (2016) (4), Estrela e Estrela (2003) (4) e Silva, Ribeiro e Risso (2009) (3).

A maior quantidade e abrangência das referências informadas pelos coordenadores de cursos com disciplina específica, em comparação aos sem disciplina específica, provavelmente está relacionada à já citada diferença no volume de tópicos sobre Biossegurança. A preferência por livros-texto, conforme observado por Catarino e Chiara (2014), procura facilitar os alunos que dependem da biblioteca da instituição para acessar os conteúdos, bem como pelo fato de inexistirem livros eletrônicos em todas as áreas do conhecimento. Além disso, livros textos são mais facilmente assimilados que outros tipos de publicação.

Dentre os manuais técnicos recomendados pelos cursos com disciplina específica, foram citados textos elaborados por instituições governamentais brasileiras (13), órgãos de classe da Odontologia (2), instituições regulamentadoras e de pesquisa (3) e autores diversos (3). Nos cursos sem disciplina específica que citaram manuais técnicos, os textos são de autoria da própria IES (3). Em geral, nos manuais técnicos constam os riscos existentes no ambiente de trabalho, assim como as práticas e procedimentos de Biossegurança necessários à minimização ou eliminação da exposição aos riscos inerentes à atividade. 
Percebeu-se que a maioria das IES revisam rotineiramente a bibliografia indicada aos alunos. Os cursos com disciplina específica citaram como periodicidade da revisão: a cada 6 meses (4), entre 6 e 12 meses (21), entre 12 e 18 meses (7), entre 18 e 24 meses (6), mais de 24 meses (4) e não informado (1). Nos cursos sem disciplina específica, a revisão da bibliografia ocorre entre 6 e 12 meses (2); entre 12 e 18 meses (9); entre 18 e 24 meses (2); mais de 24 meses (6); nunca é atualizado (2); não informado (4).

A relevância da bibliografia reside no fato de ser o meio pelo qual o aluno poderá buscar informações adicionais sobre o seu assunto de interesse (CATARINO; CHIARA, 2014). Por isso, a atualização sistemática das referências permite mantê-las adequadas às exigências da formação, bem como acompanhar mudanças nos projetos pedagógicos das IES, nas normas/legislações pertinentes e nas exigências dos órgãos fiscalizadores do Ministério da Educação (MEC) (BRASIL, 2017) e, desta maneira, fomentar e satisfazer as necessidades de informação do aluno.

Periodicamente, as IES do Brasil são avaliadas pelo MEC, visando à renovação da autorização de funcionamento. Um dos critérios de análise consiste na avaliação do acervo bibliográfico, que precisa estar em conformidade com a bibliografia citada nos planos de ensino. Nesse sentido, esta pesquisa considera que a revisão das referências bibliográficas dos cursos deve seguir pelo menos a mesma periodicidade das avaliações do MEC, de modo a evitar a indicação de textos obsoletos e também contribuir para uma melhor avaliação do curso. Às IES, assim como aos docentes, cabe a responsabilidade pela atualização permanente dos conhecimentos, atenção à evolução da ciência, busca por novas ideias e compreensão da realidade atual (LACERDA; SANTOS, 2018).

\subsection{Cursos com disciplina específica para o ensino de Biossegurança}

Foram identificadas 28 nomenclaturas diferentes para a disciplina, conforme demonstrado no quadro 3. 
Quadro 3 - Modos de oferta e nomenclaturas da disciplina específica para o ensino de Biossegurança nas faculdades de Odontologia investigadas, Brasil, 2019.

\begin{tabular}{|c|l|}
\hline $\begin{array}{c}\text { Modo de oferta } \\
\left(\mathbf{N}^{\circ} \text { cursos }\right)\end{array}$ & \multicolumn{1}{|c|}{ Nomenclaturas } \\
\hline $\begin{array}{c}\text { Biossegurança acompanhado ou } \\
\text { não de termo aludindo à } \\
\text { Odontologia (16) }\end{array}$ & $\begin{array}{l}\text { Biossegurança; Biossegurança em Odontologia; Biossegurança } \\
\text { Odontológica; Biossegurança Aplicada à Odontologia }\end{array}$ \\
\hline $\begin{array}{c}\text { Associada à Ergonomia } \\
(8)\end{array}$ & $\begin{array}{l}\text { Biossegurança e Ergonomia; Ergonomia e Biossegurança; Ergonomia em } \\
\text { Odontologia e Biossegurança; Princípios Básicos de Ergonomia e } \\
\text { Biossegurança }\end{array}$ \\
\hline $\begin{array}{c}\text { Associada à Ergonomia e à } \\
\text { Saúde do Trabalhador (1) }\end{array}$ & Biossegurança, Ergonomia e Saúde do Trabalhador \\
\hline $\begin{array}{c}\text { Associada a outra disciplina } \\
(4)\end{array}$ & $\begin{array}{l}\text { Bioética e Biossegurança; Biossegurança e Introdução à Clínica; } \\
\text { Biossegurança e Saúde Ambiental; Gestão em Saúde e Biossegurança }\end{array}$ \\
\hline $\begin{array}{c}\text { Sem menção ao termo } \\
\text { Biossegurança } \\
(14)\end{array}$ & $\begin{array}{l}\text { Orientação profissional; Orientação Profissional e Ergonomia; Pré-Clínica; } \\
\text { Pré-Clínica Odontológica; Prática profissional: ciência e Odontologia; } \\
\text { Práticas Profissionais; Atenção Integrada em Odontologia I; Atenção Primária } \\
\text { a Saúde; Clínica Integrada de Atenção Básica; Integralidade da Atenção à } \\
\text { Saúde; Introdução à Clínica Odontológica; Microbiologia Bucal; Odontologia } \\
\text { e meio ambiente; Seminários Integrados I }\end{array}$ \\
\hline
\end{tabular}

Este resultado mostra-se em consonância com o objetivo da Biossegurança que, para proteger o $\mathrm{CD}$, a equipe e os pacientes contra os agentes de risco presentes na prática odontológica, recomenda a adoção de medidas de controle dos riscos ocupacionais e de controle da infecção, práticas ergonômicas e desempenho ético com preocupações sociais e ambientais (ANVISA, 2006). A associação da Biossegurança com a Ergonomia é a mais frequente nos cursos de graduação em Odontologia brasileiros (MOIMAZ et al., 2019), interface que também é encontrada na Universidade Nacional de Córdoba - Argentina (2020).

A pesquisa pela forma de organização da disciplina de Biossegurança no currículo dos cursos identificou-se que, semestralmente, a disciplina apresentava uma média de 45 alunos/turma, com um mínimo de 15 alunos e um máximo de 80 . O ciclo da disciplina era anual em 6 cursos e semestral em 37.

Para os cursos de ambos os ciclos, anual e semestral, verificou-se uma carga horária média de 50 horas/aula, com carga horária mínima de 15 horas/aula. Já a carga horária máxima foi de 90 horas/aula para os cursos com ciclo anual e de 128 horas/aula para os de ciclo semestral. Um coordenador citou o reforço da transmissão dos conhecimentos de Biossegurança em todas as clínicas integradas, que não contabilizava para a carga horária da disciplina de Biossegurança.

Uma aula costuma ter quatro horas de duração. As DCN (2018) determinam que $20 \%$ da carga horária total do curso deve ser destinada a estágio supervisionado, o qual não pode estar incluído na carga horária das atividades práticas. Assim, estima-se que a carga horária 
destinada a aulas teóricas e práticas nos cursos investigados seria: média de 40 horas/aula (10 aulas), mínimo de 12 horas/aula (3 aulas), máximo de 72 horas/aula (18 aulas) para os de ciclo anual e de 102,4 horas/aula (25,6 aulas) para os semestrais.

As cargas horárias para o ensino de Biossegurança mais comumente citadas na literatura são as de 30 e 45 horas/aula em um semestre Toassi (2008); Razaboni (2008). Para Razaboni (2008), quando há mais de um período da mesma disciplina, deve-se evitar que o docente seja o mesmo nos dois tempos para não ficar repetitivo, e que sejam empregadas metodologias ativas de aprendizagem para evitar a perda de interesse dos alunos dos períodos mais adiantados e que já se encontram em aulas essencialmente práticas. Diante da relevância da Biossegurança na prática odontológica, pode-se supor que 15 horas/aula, conforme verificado em alguns cursos, sejam insuficientes para transmitir conhecimentos e treinar exitosamente os alunos.

Houve variação no semestre/período de oferta da disciplina, com predomínio dos iniciais: $1^{\mathrm{o}}$ semestre (7); $2^{\mathrm{o}}$ semestre (11); $3^{\circ}$ semestre (13); $4^{\mathrm{o}}$ semestre (7); $5^{\circ}$ semestre (2); $6^{\circ}$ semestre (2); $10^{\circ}$ semestre (1).

É senso comum a recomendação de que o processo formativo em Biossegurança seja iniciado nos primeiros períodos do curso (GOMES et al., 2014; LAGES et al., 2015; LOPES et al., 2019; MANCINI; REVILL, 2008), conforme ocorre em algumas IESs de países do Mercosul (UCU, 2020; UNA, 2019; UNC, 2020), de modo a construir uma sólida base teórica, promotora de uma cultura de consciência e responsabilidade, que garanta aos alunos uma entrada mais confiante nas atividades clínicas. Porém, é preciso atentar para o fato de que certos aprendizados fundamentais nos períodos iniciais (básicos), como é a Biossegurança, precisam estar articulados com o período profissionalizante (NORO et al., 2017). Nesse contexto, estudos destacaram a necessidade de reforçar o ensino da Biossegurança ao longo de todo o curso, especialmente nas disciplinas que envolvem atividades práticas, para fortalecer a sensibilização e a sedimentação dos conhecimentos atitudes e práticas dos alunos e futuros profissionais (ARANTES et al., 2015; LAGES et al., 2015; TREZENA et al., 2019).

Verificou-se que em 11 cursos havia outra disciplina como pré-requisito para a específica sobre Biossegurança, enquanto em 32 não havia pré-requisito. Também foi verificado que em 26 cursos, a disciplina específica para o ensino de Biossegurança era prérequisito para outra disciplina - sendo 20 profissionalizantes - e em 17 cursos não era prérequisito para outras disciplinas.

É recomendado evitar a quantidade excessiva de pré-requisitos e manter somente as disciplinas imprescindíveis ao aprendizado crescente, de modo a fornecer certa flexibilidade e autonomia de escolha aos alunos (BRASIL, 2000; TOASSI et al., 2012). Porém, tendo em 
vista a relação direta da Biossegurança com a segurança do exercício da Odontologia, considera-se indispensável que esta disciplina seja pré-requisito para aquelas que envolvem atividades práticas.

\subsection{Cursos sem disciplina específica para o ensino de Biossegurança}

Em 25 cursos desse grupo, a Biossegurança fazia parte do conteúdo programático de alguma outra disciplina. Somente um coordenador informou que o curso não incluía tópicos de Biossegurança em outra disciplina.

As disciplinas não específicas, com nomenclaturas variadas, que continham tópicos de Biossegurança em seu conteúdo programático compunham três grupos: com atividades práticas (20), preparatórias para a prática (6), teóricas (11) e outras (3).

A estratégia interdisciplinar é fundamentada na competência de cada especialista e no diálogo constante entre estes, os quais devem atuar de forma articulada, com disponibilidade para colaborações e troca de saberes, tendo como objeto a elaboração e implantação dos planos de ensino interdisciplinares, respeitando as especificidades e a qualidade de cada disciplina (ALMEIDA FILHO, 2014). Assim, é possível dizer que para as IES há o desafio de estabelecer e manter o diálogo, a integração e a troca de saberes entre os docentes, visando à uma formação com excelência acadêmica, pautada em princípios éticos e humanistas.

Pode-se apontar como limitação deste estudo o fato de não terem sido encontradas publicações sobre o assunto oriundas de outros países, além do Brasil, que permitissem comparar o ensino de Biossegurança na formação de CDs brasileiros com os de outras nacionalidades. Por outro lado, a força do estudo reside no fornecimento de informações que podem contribuir para o aprimoramento do ensino da Biossegurança na Odontologia, além de mostrar que na literatura há um gap de estudos sobre esse tema, especialmente em outros países, os quais seriam contribuições importantes para a discussão sobre a forma como os futuros profissionais estão sendo preparados para enfrentar os riscos ocupacionais da Odontologia.

\section{Conclusão}

A maioria das IES investigadas mantém um processo formativo empenhado em transmitir conhecimentos e treinar seus alunos acerca da Biossegurança. Algumas deveriam ampliar os tópicos sobre Biossegurança abordados e/ou aperfeiçoar o ensino sobre o tema ao longo do curso.

Considera-se que o ideal seja a presença de uma disciplina específica para Biossegurança, de caráter obrigatório, na matriz curricular dos cursos de graduação em 
Odontologia, no primeiro ano do curso. Como a Biossegurança abrange uma série de princípios e práticas interdisciplinares na busca do atendimento integral do paciente, vê-se a nomenclatura "Biossegurança" como adequada para identificar o conteúdo da disciplina.

Mesmo sendo específica, a disciplina não deve perder a essência interdisciplinar. Nesse sentido, a disciplina Biossegurança deve ser responsável por fornecer a todos os alunos os conhecimentos e treinamentos necessários, bem como por auxiliar no direcionamento das atividades de sensibilização e consolidação dos conhecimentos, atitudes e práticas em outras disciplinas, especialmente nas que envolvem atividades práticas.

Com base nos resultados e na literatura sobre o tema, acredita-se que os seguintes tópicos sobre Biossegurança sejam essenciais no processo formativo dos cirurgiões-dentistas: - Acidente de trabalho com exposição a material biológico: prevenção e conduta pós-acidente;

- Antissepsia da boca do paciente;

- Barreiras físicas de proteção;

- Conceitos, fundamentos e relação com outras disciplinas;

- Desinfecção dos equipamentos e do ambiente;

- Doenças ocupacionais transmissíveis e não transmissíveis na Odontologia;

- EPI;

- Ergonomia na prática odontológica;

- Fontes e rotas de contaminação no ambiente odontológico;

- Gerenciamento de resíduos de serviços de saúde;

- Higienização das mãos;

- Imunização (obrigatória para todos os alunos, docentes e demais envolvidos nas atividades clínicas);

- Leis e normas;

- Manifestações bucais de doenças infecciosas;

- Manuseio e descarte adequado de perfurocortantes;

- Processamento de instrumentais odontológicos: procedimentos pré-esterilização (descontaminação, limpeza, secagem, inspeção visual, embalagem), monitoramento dos ciclos de esterilização (indicadores físicos, químicos e biológicos), esterilização do instrumental (meios físicos, químicos e físico-químicos);

- Proteção da equipe de saúde;

- Qualidade da água e do ar;

- Qualidade de vida no trabalho (QVT);

- Radioproteção; 
- Riscos ocupacionais na Odontologia;

- Segurança do paciente.

Desta feita, buscou-se incentivar o aprimoramento do ensino da Biossegurança na Odontologia e, consequentemente, contribuir para a formação de cirurgiões-dentistas capazes de articular os conhecimentos adquiridos e, de forma crítica e humanizada, prestar um atendimento integral ao paciente. Espera-se que os coordenadores dos cursos de formação em Odontologia compreendam a importância desta temática para a saúde e segurança do cirurgiãodentista, assim como dos pacientes e do ambiente, e insiram/aprimorem o ensino da Biossegurança no currículo da IES sob suas responsabilidades

\section{Referências}

ANVISA - AGÊNCIA NACIONAL DE VIGILÂNCIA SANITÁRIA. Serviços odontológicos: prevenção e controle de riscos. Brasília: Ministério da Saúde, 2006.

ALMEIDA FILHO, Naomar. Interdisciplinaridade na Universidade Nova: desafios para a docência. In: CERVI, Giceli; RAUSCH, Rita Buzzi (eds.). Docência universitária: concepções, experiências e dinâmicas de investigação. Blumenau: Meta, 2014. p. 21-28.

ADA - AMERICAN DENTAL ASSOCIATION. What constitutes a dental emergency? 2020. Disponível em:

https://success.ada.org/ /media/CPS/Files/Open\%20Files/ADA_COVID19_Dental_Emergen cy_DDS.pdf. Acesso em: 7 maio 2020.

ARANTES,_Diandra Costa et al. Biossegurança aplicada à Odontologia na Universidade Federal do Pará, Cidade de Belém, Estado do Pará, Brasil. Revista Pan-Amazônica de Saúde, Ananindeua, v. 6, n. 1, p. 11-18, 2015.

ARMOND, Anna Catharina Vieira et al. Conhecimentos de biossegurança para as principais atividades de risco envolvendo servidores públicos, discentes e empregados da limpeza do curso de Odontologia da UFVJM/Diamantina. Revista Brasileira de Odontologia Legal, São Paulo, v. 3, n. 2, p. 32-52, 2016.

BELLISSIMO-RODRIGUES, W. T Wanessa Teixeira; BELLISSIMO-RODRIGUES, Fernando; MACHADO, Alcyone Artioli. O ensino de biossegurança na graduação em Odontologia. Revista ABO Nacional, São Paulo, v. 18, n. 4, p. 229-233, 2010.

BRASIL. MINISTÉRIO DA EDUCAÇÃO. Fórum de Pró-Reitores de Graduação das Universidades Brasileiras. Diretrizes Curriculares para os Cursos de Graduação. 2000. Disponível em: http://portal.mec.gov.br/sesu/arquivos/pdf/DocDiretoria.pdf. Acesso em: 27 ago. 2020.

BRASIL. MINISTÉRIO DO TRABALHO E EMPREGO. Portaria GM/MTE $\mathbf{n}^{\circ} \mathbf{1 . 7 4 8}$ de 30 de agosto de 2011. Brasília, 2011.

BRASIL. MINISTÉRIO DA EDUCAÇÃO. INSTITUTO NACIONAL DE ESTUDOS E PESQUISAS EDUCACIONAIS ANÍSIO TEIXEIRA (INEP). Instrumento de avaliação de cursos de graduação presencial e a distância. Brasília: Inep/MEC, 2017. Disponível em: http://inep.gov.br/instrumentos. Acesso em: 20 ago. 2020. 
BRASIL. MINISTÉRIO DA EDUCAÇÃO. CONSELHO NACIONAL DE EDUCAÇÃO (CNE). Diretrizes Curriculares Nacionais do curso de graduação em Odontologia. 2018. Disponível em:

http://portal.mec.gov.br/index.php?option=com_docman\&view=download\&alias=111231pces803-18\&category_slug=abril-2019-pdf\&Itemid=30192. Acesso em: 18 ago. 2020

CATARINO, Maria Elisabete; CHIARA, Ivone Guerreiro di. A bibliografia básica do curso de direito e a cobertura da coleção do sistema de bibliotecas da Universidade Estadual de Londrina - SB/UEL. In: SEMINÁRIO NACIONAL DE BIBLIOTECAS UNIVERSITÁRIAS, 18., 2014, Belo Horizonte. Anais [...]. Belo Horizonte, 2014.

Disponível em: https://www.bu.ufmg.br/snbu2014/wp-content/uploads/trabalhos/85-2205.pdf. Acesso em: 20 ago. 2020.

CEZARINO Luciana Oranges; CORRÊA, Hamilton Luiz. Mensuração da interdisciplinaridade nos cursos de graduação em Administração. Avaliação, Campinas; Sorocaba, v. 24, n. 1, p. 174-188, 2019. Disponível em: https://www.scielo.br/j/aval/a/HGL9GHtCYQTtvv7qBHRNTHn/?lang=pt. Acesso em: 11 set. 2020

COSTA NETO, Odorico Coelho. Construção de um modelo curricular para o curso de graduação em Odontologia a partir de paradigmas estruturais e conjunturais contemporâneos. Dissertação (Mestrado) - Programa de Pós-graduação em Odontologia, Universidade Federal de Uberlândia, Uberlândia, 2006.

ESTRELA, Carlos; ESTRELA, Cyntia R. A. Controle de infecção em odontologia. São Paulo: Artes Médicas, 2003.

EU-OSHA. EUROPEAN AGENCY FOR SAFETY AND HEALTH WORK. Occupational hazards in dental clinics - Safety and health at work - EU-OSHA. Disponível em: https://osha.europa.eu/en/themes/dangerous-substances/practical-tools-dangeroussubstances/occupational-hazards-dental-clinics. Acesso em: 15 abr. 2020.

GOMES, Letícia Carneiro et al. Biossegurança e resíduos de serviços de saúde no cotidiano acadêmico. Revista de Ciências Farmacêuticas Básica e Aplicada, São Paulo, v. 35, n. 3, p. 443-450, 2014.

HIRATA, Mario Hiroyuki; HIRATA, Rosario Dominguez Crespo; MANCINI FILHO, Jorge. Manual de biossegurança. Barueri: Manole, 2016.

KUHN, Claudio Rafael et al. Contaminação microbiana em consultórios odontológicos. Revista Brasileira de Ciências da Saúde, João Pessoa, v. 22, n. 4, p. 315-324, 2018.

LACERDA, Flávia Cristina Barbosa; SANTOS, Letícia Machado. Integralidade na formação do ensino superior: metodologias ativas de aprendizagem. Avaliação, Campinas; Sorocaba, v. 23, n. 3, p. 611-627, 2018. Disponível em:

https://www.scielo.br/j/aval/a/JRjdzXYGrSdQSZmDxFQQwdM/abstract/?lang=pt. Acesso em: 11 set. 2020

LAGES, Silvana Maria Ramos et al. Formação em Odontologia: o papel das instituições de ensino na prevenção do acidente com exposição a material biológico. Ciencia \& Trabajo, Santiago, v. 17, n. 54, p. 182-187, 2015.

LOPES, Amanda Lívia et al. Biossegurança em Odontologia: conduta dos estudantes antes e após uma ação educativa. Revista da ABENO, Porto Alegre, v. 19, n. 2, p. 43-53, 2019. 
MANCINI, Giulio; REVILL, James. Fostering the biosecurity norm: biosecurity education for the next generation of life scientists. Como-Italy / Bradford-UK, 2008. Disponível em: http://sro.sussex.ac.uk/39517/1/Fostering.pdf. Acesso em: 14 ago. 2017.

MAZUTTI, William José; FREDDO, Silvia Leticia; LUCIETTO, Deison Alencar. Acidentes perfurocortantes envolvendo material biológico: o dizer e o fazer de estudantes de um curso de graduação em Odontologia. Revista da ABENO, Porto Alegre, v. 18, n. 4, p. 21-30, 2018. MEIRELES, Jaqueline Fernanda; LINDINO, Terezinha Corrêa. Formação disciplinar ou transversal: qual delas promove melhor percepção ambiental entre universitários? Revista Pleiade, Foz do Iguaçu, v. 13, n. 29, p. 18-29, 2020.

MPT - MINISTÉRIO PÚBLICO DO TRABALHO; ORGANIZAÇÃO INTERNACIONAL DO TRABALHO. OIT. Smartlab - Observatório de Segurança e Saúde no Trabalho. Disponível em: https://smartlabbr.org/sst. Acesso em: 13 abr. 2020.

MOIMAZ, Suzely Adas Saliba et al. Professional guidance in brazilian dental education. Revista da ABENO, Porto Alegre, v. 19, n. 3, p. 50-57, 2019.

MORAES, Bibiana Arantes; COSTA, Nilce Maria da Silva. Compreendendo os currículos à luz dos norteadores da formação em saúde no Brasil. Revista da Escola de Enfermagem da USP, São Paulo, v. 50, n. especial, p. 9-16, 2016.

MUSSI, Marcelo; MARASEA, Daniela Carnio Costa. A perspectiva da subnotificação de acidentes ocupacionais com dentistas. Revista Brasileira de Odontologia, Rio de Janeiro, v. 73, n. 2, 2016.

NARESSI, Wilson Galvão; ORENHA, Eliel Soares; NARESSI, Suely Carvalho Mutti. Ergonomia e biossegurança em Odontologia. São Paulo: Artes Médicas, 2013. Série Abeno: Odontologia Essencial - Parte Clínica.

NOGUEIRA, N. et al. Prevalência e notificações de acidentes de trabalho com exposição a material biológico na Odontologia. Revista Ciência Plural, Natal, v. 2, n. 1, p. 102-119, 2016.

NORO, Luiz Roberto Augusto et al. Relação entre conteúdos das disciplinas de curso de Odontologia e os ENADE 2004/2010. Avaliação, Campinas; Sorocaba, v. 22, n. 1, p. 125139, 2017. Disponível em:

https://www.scielo.br/j/aval/a/wYSbrK6vnHcTWhYjhVVqzJQ/?lang=pt. Acesso em:

OLIVEIRA, Ana Paula Costa. Competências gerenciais de professores-gestores do ensino superior: um estudo comparativo entre coordenadores de instituições públicas e privadas de Belo Horizonte (MG). Dissertação (Mestrado) - Universidade Federal de Minas Gerais, Belo Horizonte, 2018.

OLIVEIRA, Augusto Henrique Alves et al. Uso de equipamentos de proteção individual por cirurgiões-dentistas em Unidades Básicas de Saúde: estudo piloto. Revista Interfaces, Juazeiro do Norte, v. 5, n. 15, p. 64-70, 2017.

UNESCO - ORGANIZAÇÃO DAS NAÇÕES UNIDAS PARA A EDUCAÇÃO, A CIÊNCIA E A CULTURA. Glossário de terminologia curricular. Paris: UNESCO, 2016.

PIMENTEL, M. J. Marcele Jardim et al. Biossegurança: comportamento dos alunos de Odontologia em relação ao controle de infecção cruzada. Cadernos Saúde Coletiva, Rio de Janeiro, v. 20, n. 4, p. 525-532, 2012. 
RAZABONI, Ana Maria. Avaliação de conteúdo programático: proposta de ensinoaprendizagem em biossegurança. Tese (Livre Docência) - Universidade de São Paulo, Ribeirão Preto, 2008.

RIBEIRO, Maristela Azevedo. Avaliação da necessidade de implantação de normas e rotinas de Biossegurança para a qualificação dos estudantes do curso de Odontologia. Dissertação (Mestrado) - Universidade Federal de Santa Catarina, Florianópolis, 2004.

ROCHA, M. A. M.; SCHUH, M. S.; MACHADO, J. D. de D. A percepção dos coordenadores de curso da área da saúde sobre os fatores que influenciam no engajamento dos graduandos. In: CONGRESSO IBERO-AMERICANO DE DOCÊNCIA UNIVERSITÁRIA, 10., 2019, Porto Alegre. Anais [...]. Porto alegre: EDIPUCRS, 2019. Disponível em:

$<$ https://editora.pucrs.br/acessolivre/anais/cidu/assets/edicoes/2018/arquivos/48.pdf>. Acesso em: 3 ago. 2020

SILVA, Almenara Souza Fonseca; RIBEIRO, Mariângela Cagnoni; RISSO, Marine. Biossegurança em Odontologia e ambientes de saúde. São Paulo: Icone, 2009.

ŞOAITA, Claudia. Identifying occupational risks in dentistry. Procedia Technology, Amsterdã, v. 12, p. 558-565, 2014.

SOUZA, Fábio Barbosa; LOPES, Maria Gabriela Quadros; LIMA FILHO, Rivaldo Mendes. Redes sociais na aprendizagem em Odontologia: opinião dos estudantes de uma universidade brasileira. Revista Cubana de Estomatología, Havana, v. 54, n. 2, p. 1-11, 2017.

TAVARES, Maria de Fátima Lobato et al. A promoção da saúde no ensino profissional: desafios na saúde e a necessidade de alcançar outros setores. Ciência \& Saúde Coletiva, Rio de Janeiro, v. 21, n. 6, p. 1799-1808, 2016.

TOASSI, R. F. C. O embate do processo de implantação de um currículo modular na educação superior: o curso de Odontologia da UNIPLAC, Lages - SC. 2008. Tese (Doutorado) - Pontifícia Universidade Católica do Rio Grande do Sul, Porto Alegre, 2008.

TOASSI, Ramona Fernanda Ceriotti et al. Avaliação curricular na educação superior em Odontologia: discutindo as mudanças curriculares na formação em saúde no Brasil. Revista da ABENO, Porto Alegre, v. 12, n. 2, p. 170-177, 2012.

TREZENA, Samuel et al. Medidas de precaução padrão adotadas em uma clínica escola de graduação em odontologia. HU Revista, Juiz de Fora, v. 45, n. 2, p. 148-155, 2019.

UCU - UNIVERSIDAD CATÓLICA DEL URUGUAY. Plan di estudios y horarios. Disponível em: https://carreras.ucu.edu.uy/index.php/carreras/f-Odontologia/Odontologia. Acesso em: 31 ago. 2020.

UNA - UNIVERSIDAD NACIONAL DE ASUNCIÓN. FACULTAD DE ODOTOLOGÍA (). Plan de Estudio Curricular 2019. Disponível em: http://proyectos.com.py/odo/wpcontent/uploads/2019/03/Plan-Curricular-2019-Original.pdf. Acesso em: 31 ago. 2020.

UNC - UNIVERSIDAD NACIONAL DE CÓRDOBA. FACULTAD DE ODONTOLOGÍA. Odontología. Lista de Cátedras. Disponível em:

https://www.odo.unc.edu.ar/academico/grado/catedras/lista-de-catedras\#. Acesso em: 31 ago. 2020.

VASCONCELLOS, Liliana; GUEDES, Luis. E-Surveys: vantagens e limitações dos questionários eletrônicos via internet no contexto da pesquisa científica. In: SEMEAD -

SEMINÁRIOS EM ADMINISTRAÇÃO FEA/USP. 10., 2007, São Paulo. Anais [...]. São

Paulo: EdUSP, 2007. 
ZENKNER, Clacir Lourdes Londero. Proposta de gestão de riscos para o controle de infecção, a partir do diagnóstico de biossegurança, nas clínicas do curso de odontologia da UFSM. 2006. Dissertação (Mestrado) - Universidade Federal de Santa Maria, Santa Maria, RS, 2006. 